\title{
Developing and Applying Knowledge and Skills in Ethics and Professional Morality: An Evidence-Based Practice Paper
}

\section{Dr. Donald Winiecki, Boise State University}

Don Winiecki, Ed.D., Ph.D. is the 'Professor of Ethics \& Morality in Professional Practice' in the Boise State University, College of Engineering. He teaches undergraduate and graduate courses in 'Foundational Values' and 'Professional Ethics' in the Computer Science Department and Organizational Performance \& Workplace Learning Department in the Boise State University College of Engineering. His research focuses on the attributes of technology and technology-in-use as a reflection on, and an influence on social morals and social ethics.

\section{Mr. Lynn Catlin P.E., Boise State University \\ Dr. Harold Ackler, Boise State University}

Dr. Harold Ackler is a Clinical Assistant Professor in the Micron School of Materials Science and Engineering at Boise State University. He teaches advanced undergraduate laboratory courses and manages the senior capstone program in the Micron School. He received BS and MS degrees from the University of California at Berkeley and his PhD degree from the Massachusetts Institute of Technology (1997), all in Materials Science and Engineering. He has over 13 years of experience working in industry where he learned how important hands-on education and professional development are for preparing students to succeed in the workplace. 


\section{Developing and Applying Knowledge and Skills in Ethics and Professional Morality}

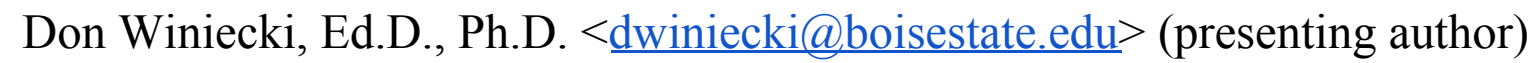

Lynn Catlin, P.E. <lynncatlin@,boisestate.edu>

Gus Engstrom, Ph.D., P.E. < gusengstrom@boisestate.edu>

Harold Ackler, Ph.D. < hackler@,boisestate.edu $>$

Boise State University, College of Engineering

Boise, Idaho USA

Accepted for presentation in the "Engineering Ethics" track at

American Society for Engineering Education (ASEE) 2020

(Originally scheduled for 21-24 June, Montreal, QC, Canada // Site-based conference canceled due to COVID-19 // Presented in Online Venue provided by ASEE) 


\title{
Developing and Applying Knowledge and Skills in Ethics \& Professional Morality
}

\begin{abstract}
Even without a focused interest in the topic, as we enter the third decade of the 21 st Century one would have a difficult time ignoring the steady flow of stories reporting tragic consequences arising from engineering decisions that appear to have omitted ethical components, and of ethical dilemmas arising from contemporary engineering and computer science. Similarly, one would have to be willful to miss an equally steady drumbeat of calls for improved ethics in engineering and computer science education.

However, one can make the argument that simply offering new or more content related to ethics in engineering education is not enough. With an eye on engineering a response to these issues, we propose that systemic changes are warranted including who presents and guides ethics content, how students are brought face-to-face with ethics and how ethics content is threaded into a curriculum, and how the real and existential outcomes of engineering decisions are assessed both in design stages and in professional applications.

This case study report describes efforts to introduce ethics into the engineering practice expected of students in undergraduate Senior Design courses through the work of a sociologist "embedded" in a College of Engineering. We identify and describe our intellectual framework, instructional methods, student assignments, and report early evaluations based on objective measures and student comments.
\end{abstract}

Status Quo: Needs, Processes, Gaps, Prospective Solutions

In undergraduate education, engineering ethics is often taught in titular courses by individuals with advanced degrees in engineering. It is not common to find that such individuals also have substantive academic or professional preparation in topics related to ethics. Perhaps because it is often not considered to be part of the core of engineering education, engineering ethics courses are also often assigned as a "service course" taught by entry-level or non-tenure-track faculty. For this reason many engineering ethics courses are built around content provided in a common slate of textbooks prepared by individuals who have the requisite academic or professional preparation and experience [1]-[5]. ${ }^{1}$

These textbooks often approach the topic of engineering ethics in terms of case studies of disasters occurring as a consequence of lapses in professional judgment, or from a cascade of possible but calculably improbable events (for example, Tacoma Narrows bridge ${ }^{2}$, Missouri hotel

\footnotetext{
${ }^{1}$ It may in fact be ideal for all instructors to be professional engineers with substantive experience in the field and with the types of ethical dilemmas faced in professional practice. This would allow the instructor to act as a highly credible guide through both technical content and the less technical aspects of professional ethics. However, while this might be ideal, it is perhaps not a real "possible possibility" in most cases. As a consequence, we have to find other ways of getting this job done.

${ }^{2}$ https://en.wikipedia.org/wiki/Tacoma_Narrows_Bridge
} 
mezzanine $^{3}$, NASA Challenger ${ }^{4}$, Deep Water Horizon oil well explosion ${ }^{5}$, Volkswagen diesel $\underline{\text { defeat device }}^{6}$, etc.). These case studies are usually framed in terms of normative ethics (i.e., when some decision or some part of engineering can be argued to be absolutely-okay or absolutely-not-okay, irrespective of context) and the costs of engineering failures. Activities prescribed by these sources commonly guide students to adopt the perspective of normative ethics within morality-play examples that pit one ethical theory with another (for example, utilitarianism vs. rights, or vs. common good, etc.). The result often approaches ethics as a puzzle that can be solved with engineering logic if one has the data necessary to "engineer risks out of the system." While there is certainly value in demonstrating to aspiring engineers how problems have occurred in the past so we emphasize the value of professional due diligence, there is much more to ethics in engineering than a retrospective analysis in terms of absolutes.

This is the same in our case, where students are introduced to professional ethics in readings and assignments in a course required in their first or second year of undergraduate engineering education. This course is an application overview that uses case studies that uses what could be considered obvious cases of professional misconduct and breach of due-diligence expectations. Students review one or more of the cases (often one of those listed above) and write a brief essay describing the professional ethical breaches demonstrated in that case. One faculty member described that this exercise "...is really pretty easy... the case study gives a long view that makes the overall problems apparent even though those problems might have been very obscure if you were in the middle of it."

Additionally, the application of ethics is not necessarily something that requires selection of the "right" normative model, framework, or theory. Ethical conduct often requires that we pay attention to contextual factors that are outside of technical concerns, as well as disciplinary facts and norms. This makes the case that ethical conduct and decision-making requires a commitment to professional morality from the standpoint that engineers are protectors of the public and not just or not only individuals who follow normative prescriptions [6]-[8].

It is also relevant to admit that undergraduate engineering students (and entry level engineering professionals) know they are not in a position to make design or implementation decisions that could have the sort of monumental effects illustrated in textbook cases. With this in mind, it is unsurprising that students sometimes protest that engineering ethics courses are a distraction from their priority to improve technical skills because they believe - for better or worse - that it is those technical skills alone which will make them employable and make them a successful engineer [9].

Finally, it is common to find that engineering ethics is concentrated in a single course at the sophomore level in an otherwise very tightly packed technical curriculum. While other faculty are not officially discouraged from incorporating ethics into their curricula, the fact that

\footnotetext{
${ }^{3}$ https://en.wikipedia.org/wiki/Hyatt_Regency_walkway_collapse

${ }^{4}$ https://en.wikipedia.org/wiki/Space_Shuttle_Challenger_disaster

${ }^{5}$ https://en.m.wikipedia.org/wiki/Deepwater_Horizon

${ }^{6} \mathrm{http}: / /$ Volkswagen_emissions_scandal
} 
professional program accreditation requires substantive and thorough coverage of technical topics puts pressure against doing so [9].

All of this suggests that - even if engineering ethics content is relevant, professionally necessary, and serves an interest in (hopefully) producing more cautious and ethical engineers organizational commitment, program accreditation pressures, and the content and methods commonly employed in off-the-shelf engineering ethics textbooks, produce a mix of factors that may result in the common finding that students often become measurably less ethical as they progress through their undergraduate career [9], [10].

In response to this, the College of Engineering at Boise State University is taking advantage of systemic curricular change efforts made possible by an NSF sponsored RED grant (Revolutionizing Engineering and Computer Science Departments) to its Department of Computer Science [11]-[17], and adapting innovations from that project to other engineering departments. This manuscript describes efforts in the Department of Mechanical and Biomedical Engineering and Micron School of Materials Science and Engineering. These efforts are beginning in the Senior Design/Capstone courses, with the goal that content and activities will gradually be filtered into other courses starting with the first-year experience. ${ }^{7}$

These efforts seek to address the gaps in engineering education noted above by (a) involving a specialist in ethics and technology in the context of engineering education, (b) embedding engineering ethics within straightforwardly "technical" courses, (c) illustrating how professional and engineering questions encountered in upper division engineering education benefit from a pan-ethical perspective, and (d) subjecting these decisions to the critical review of clients who will have to face any ethical dilemmas arising from engineering decisions.

\section{Working to fulfill the Future of Engineering Ethics \& Engineering Ethics Education}

In its updated Code of Ethics, The National Society of Professional Engineers (NSPE, 2019) puts substantive emphasis on ethics as a proactive process that defends and protects personal and societal needs and legal rights through engineered products and systems. This is a change from previous versions of the code, which were more focused on technical quality and proof of design measures. This orientation positions the engineer as a protector of the needs and rights of individuals in social systems. We might even say that the professional engineer of the future is as much a "social engineer" acting to build a safe and equitable infrastructure as an individual responsible for the design and production of equipment that behaves reliably within specified limits set by a client. Different from historical expectations, this may require an individual

\footnotetext{
${ }^{7}$ Other curriculum structures are possible, and may even be preferable. For example, curricula that includes service learning goals such as those described in the closing sections of this paper may permit a more embedded approach to ethics. Similarly, diffusing ethics content through the entire curriculum and not in just one course would provide students with many more embedded examples to ethical choices that must be made in engineering. Our approach here fits into existing and very stable curricula that are ABET Accredited, without introducing changes throughout the undergraduate curriculum. We offer this case study as evidence for how ethical analyses can be embedded into existing courses when other options may not be possible, what we can expect from this sort of process, and how we can improve our practice for the benefits of students, disciplinary departments, project sponsors, and other stakeholders.
} 
oriented more to professional morality and critical arbitration of what is the "right thing to do" given contextual factors, than to normative ethics that prescribe rules for how one applies technical knowledge and skills [8], [18], [19].

We have no doubt that engineering students and engineering faculty are capable of the sort of critical analysis required to accomplish this vision. However, learning and developing a proactive orientation to professional morality will require different skills than could likely be learned by analyzing historical cases common in textbooks that presume the application of entrenched normative ethics. "Applied Ethics" is an approach developed by the Markkula Institute at Santa Clara University. In the Markkula approach to applied ethics, five principal frameworks of ethics are imbricated in a structured approach such that one can analyze an issue, systematically build and test the ethicality of varying approaches to the issue, and ensure that the result is consistent with one's moral vision of how one "should be" as a professional [20].

It will also require that we incorporate ethics content in a way that is immediately relevant for students and which involves structured activities that help students orient to important factors and understand how those factors contribute to desired outcomes, develop confidence and receive rewards that improve the likelihood they will persist in use of the new knowledge and skills. Well-established research in instructional technology supports use of the ARCS model [21] for this purpose. ARCS is an acronym for Attention, Relevance, Confidence, Satisfaction. These four elements enable development of instruction that accomplishes the above.

Similarly, realizing the future vision for ethics in engineering will also require that faculty members have made the commitment to learn and develop the same skills. With the fact that tenure track faculty are usually committed to research, publications, and demanding teaching practice in technical aspects of engineering, the latter could be a critical systemic weakness in engineering departments that works against the success of this future.

The previously-mentioned NSF-RED project has enabled the BSU Department of Computer Science to engage a tenured social scientist (first author of this paper) to facilitate, design, development, and threading of ethics content throughout its undergraduate curriculum. Close partnership between this faculty member and other departments has aided identification of opportunities for adapting innovations from the NSF-RED project into other courses in the College of Engineering, including those described here. This individual teaches a course explicitly designed for first year Computer Science students, but also partners with faculty across Computer Science to incorporate ethics content into courses usually considered to be "only technical" in content including courses on algorithm development, blockchain, machine learning, and data science courses. Through an additional agreement with the College of Engineering, he also partners with faculty in other engineering departments to incorporate ethics content and activities. This has enabled engineering faculty to retain focus on their disciplinary specialties while also enabling ethics content to be folded into their curricula.

\section{Applied Ethics in Senior Design}

Why Applied Ethics? 
As indicated above, "applied ethics" requires one to implicate contextual features of a case as fundamental and then use and accommodate multiple ethical frameworks in a network of reasoning to determine how to proceed. Proponents of this "casuist" view assert that it provides for an assessment of a situation that is not dependent on any one ethical framework (thus not normalized or "normative" based on one framework) but requires us to imbricate many different frameworks to produce widely-grounded and widely-defensible responses to the situation [22], [23]. This is different from "normative ethics," which leads an individual to choose and apply a single ethical framework in order to determine what is the absolute ethicality of some thing, independent of context. ${ }^{8}$

As another issue suggesting that a normative ethics approach is questionable, when focusing students on normative ethics, we have observed that students will sometimes "shop for" a normative ethical theory or framework that allows them to pick and assemble facts so as to claim an ethical basis for the conclusion they already want to make, rather than to determine what would be the most ethical process or outcome. While the applied/casuist approach is not a guaranteed solution to this dilemma, because it requires one to imbricate multiple ethical frameworks, the applied/casuist approach can make it much less easy to use ethical theory in a deceitful and unethical way.

Additionally, since it is arguably the case that context always matters in making engineering decisions it is relevant to provide students with this applied/casuist perspective to ethical

\footnotetext{
${ }^{8}$ An example of the puzzles that arise occurs in the case of the MCAS system with the Boeing 737-MAX airliner. It was recently reported that a predecessor of the MCAS system installed on the 737-MAX was also in place in 737 models from the beginning of the design. These reports imply that in testing of many systems subsequent to the decision to ground the 737-MAX airframe, identified flaws in the 737-MAX version of MCAS actually also existed in a similar form in previous iterations of the software (it is more than important to note that there was no indication that Boeing was aware of these longstanding bugs prior to the recent analysis of historical systems). However, it was also reported that the design and operating characteristics of previous models of the 737 absolutely prevented those software flaws from ever being activated.
}

While engineering employs stable facts about the physical world that have been produced and verified through both scientific and engineering experimentation, the practice of engineering is also very sensitive to situational details (the same applies to the practice of law in cases where engineering projects are exposed to litigation).

With this in mind, one could consider that If previous versions of the 737 could never experience the fatal problems associated with the 737-MAX (because earlier airframes and aerodynamics could never experience the same conditions as possible in the 737-MAX), then we have (experimental and practical) evidence that no risks associated with the MCAS existed in reality prior to the 737-MAX.

This is potentially a very different conclusion than one would reach with a normative ethics approach, which could easily conclude that knowingly installing software with bugs in it in a commercial airliner where hundreds of lives are at immediate risk is always and unequivocally unethical. Providing students with experiences that address "applied ethics" in addition to the more common "normative ethics" approach, will enable us to give students.

The above is indeed a difficult case, so please also consider an analogous case: would engineers design a bridge to be resistant to earthquakes, even when that bridge was to be constructed in a region with no historical record of earthquakes and uncertain foreseeable risks (e.g. recent fracking activity in that region)? Tens of thousands of people might cross that bridge every day and we surely want it to be as designed and constructed as safely possible!

In this case the conditions are that there is no practical risk of failure due to earthquakes, so one could argue that it would be unnecessary and even wasteful to insist that in order to be an ethical engineer, the bridge designers must follow standards that would apply in a earthquake-prone location. 
decision-making. We even make the claim that in a class like Senior Design — where students are attempting to bring to bear much of their previous academic experiences with new client-facing professional skills — this orientation to applied ethics is especially appropriate. We make this claim because in the Senior Design course students encounter what may seem like a dizzying array of client-facing contextual details that may not appear immediately relevant to engineering as they have learned in previous classes, but which are still relevant to the development of engineering skills and especially professional morality as it relates to fundamental canons included in the NSPE Code of Ethics [7]. ${ }^{9}$ In effect, with a focus on applied ethics, we provide a scaffold on which ethics, professional skills, and technical skills can be joined as a fabric of components necessary to successful engineering practice.

Structuring the Lessons: ARCS and "Full Stack Ethics" as a guide

It may be no surprise that matters of professional ethics are sometimes considered by students to be outside their central focus, and even unimportant to their success as engineering students and eventually as engineers [9]. This is clearly indicated in student comments in response to our interventions (see below) and is at least in part attributable to the fact that "ethics" as a topic is rarely if ever addressed as such in their engineering courses. This allows the observation that ethics is outside of the focus of engineering. A similar separation can still be seen when this topic is siloed into the (usually) single ethics course or titular lessons in a course such as Senior Design and then not addressed at other points or woven into practice.

This indicates the primary importance of making the topic of professional ethics motivationally relevant and appealing. Drawing from firmly researched processes in instructional technology, increasing the motivational appeal of instructional content has been shown to be reliably possible using the ARCS model [21]. ARCS is an acronym that stands for Attention, Relevance, Confidence, and Satisfaction. Structuring the environment and instructional experiences to (a) focus attention on a topic, (b) demonstrate that it is relevant to students at this point in their education and in their lives, (c) help them develop confidence in applying new topical knowledge and skills, and (d) supporting satisfaction in this application, will increase the likelihood that learners will both accept the topic and employ it independently in the future.

Not only should we be attentive to students' perception of the relevance of ethics issues, but we should also ensure that students have adequate opportunity to make use of ethics content as they are working on various phases of their senior design projects. Ideally, this would then require that the content were initially introduced early in the semester, and there were regular "check up" assessments through the semester to help focus and steer students' developing knowledge and skills in applied ethics. However, in the cases described here, emergent client and curricular demands delayed introduction of the content until nearly mid-term of the first semester (in a two semester sequence). Regular assessments were incorporated into interim project deliverables and the final "Senior Showcase" poster presentations of work, as described below.

\footnotetext{
${ }^{9} \mathrm{We}$ would argue that this is also valuable in courses earlier in their undergraduate careers!
} 


\section{The Lesson: "Full Stack” Ethics}

"Full Stack Ethics" is a variant of an approach to ethical decision-making presented by the Markkula Center for Applied Ethics at Santa Clara University [20]. Central to both Markkula's and our approach is a set of five distinct frameworks for ethics: (a) utilitarian, (b) rights, (c) fairness/justice, (d) common good, and (e) virtue. Each of these frameworks could be applied in a normative ethics regime, but doing so runs the very real risks that not all members of an engineering design team would agree with the framework chosen, interpretation of the critical elements of the chosen framework, or resulting decisions; or as indicated above, allowing individuals to bypass the intended process and "shop for" an ethical framework with which they can weave a solipsism that more-or-less ratifies the decision already desired.

By asking questions implied by each of these five different frameworks in the sequence indicated above, it is possible to create the conditions of a discussion that starts with the usual engineering focus on utility, but which also requires a team to consider legal and societal norms of rights, socio-economic and other concerns with respect to justice/fairness, societal, regional, and political concerns over common good produced (or hurt) by an engineering innovation, and then an ultimate assessment if the products of utility, rights, justice/fairness, and common good allow an individual or team to reflect their professional virtues personally and/or as expected in the professional codes of ethics (e.g., [7]).

This sequence - utility, rights, justice/fairness, common good, virtue - is suggested by Markkula for guiding decisions about the ethicality of things analogous to engineering projects. Markkula even provides a browser-based tool that can be used to guide this sequence [23].

Alternatively, the sequence can be reversed (i.e., virtue, common good, justice/fairness, rights, utility) in order to focus students on a more personal approach to applied ethics. This sequence puts personal virtue (what you personally value) as the first gate in the series. Leading one's decisions with an interrogation of case details as they would or would not help to fulfill an individual's personal moral commitments can have the effect of conditioning subsequent decisions to ensure that no matter what might arise is always consistent with ideals and values you want to fulfill as an individual and professional. In either sequence this process represents the "full stack" of ethical frameworks rather than just one, and requires users to accommodate elements of each in any decision with respect to ethicality.

Regardless, the approach does not itself produce defensible outputs unless users are familiar with at least the basic elements of each component normative framework. While it is common for engineering programs to require one ethics course - perhaps offered as an elective by the Philosophy department - such courses are also electives for many disciplines and may not provide examples and applications that are immediately recognized to be relevant for engineering students. As noted, this argues for customized instruction so that concepts and frameworks are perceived to be relevant.

For this reason, we begin the curricular module on applied ethics with an interactive lesson that reviews the five ethical frameworks named above and interleaves them with students' current 
projects through a series of informal debriefing conversations with teams in a whole-class meeting. This is done such that we fulfill Keller's ARCS instructional framework to increase the relevance and motivational appeal of applied ethics in engineering [21]. Prior to this lesson, students are asked to read and consider brief descriptions of each of the ethical frameworks. Each of these five readings is no more than three pages in length. This means it does not introduce a substantive burden on students already busy with many academic (and possibly professional) concerns.

\section{Step 1: Gain Attention and Establish Relevance for Applied Ethics}

At the start of the lesson, the instructor asks teams in the Senior Design course to describe their projects. Questions from the instructor to team members ask about details that relate to some of the five ethical frameworks. This engages a process in which things the students currently know and value (details about their projects) is blended with new information on professional ethics.

For example, a team working on development of improved air-filtration systems and lighter and less-expensive PPE for workers in a facility that generates a lot of organic dust could be asked about the rights of workers to a safe environment (a question of rights) as compared to the fact that relatively few workers are actually exposed to the risk (a utility calculation). Students will invariably mention that the cost of lawsuits for violating OSHA regulations - a risk to the organization - should also be considered in a utility calculation. This demonstrates how the new combination of rights and utility provides for a more broadly grounded basis for decision-making than either does alone. Additional questions about the common good associated with providing both universal and individual protections to workers can then be introduced. Students might mention that with a company's demonstration that the system and its equipment are engineered together to protect them as well as provide for corporate goals (a common good orientation), workers could come to have greater trust in the organization, thus perhaps greater commitment. When asked if an engineer should be willing to consider this breadth of factors as they affect not just the organization but also the wellbeing of individuals, students respond in the affirmative that in fact this is a virtuous process.

A team working on automating a high-repetition, and high-risk task with custom robotic technology is asked about the utility of automating multiple human workers; then about the common good that might be threatened by replacing human workers; then about the common good that arises when high-risk tasks are no longer undertaken by humans; then about fairness as realized by reducing the cost of products (for example, by reducing errors and reducing the organizational and personal cost of worker injuries) so they may be afforded by more individuals; then about the improvement of workers' rights to safety by not being exposed to high-risk job duties. When asked if attending to each of these different ethical edges is something that a good (or virtuous) engineer would do, they respond in the affirmative. This apparently meandering case is then retrospectively shown to represent a very stable and interconnected network of technical, corporate, personal, and even societal factors, and that the interconnections between these issues is established and solidified by ethical concerns. 
Blending of details with which students are familiar, comfortable, and confident, with new information that may not be considered germane is critical in this step. By imbricating these two categories of information and associated knowledge and skill we create an environment in which it becomes possible to accept the argument that professional ethics and successful engineering are continuous parts of professional practice.

While the examples above may be straightforward, we have to admit that responding to student project details with relevant questions requires more than nominal familiarity with the ethical frameworks and this instructional process. So far, all deliveries of this lesson have been accomplished by the first author - a sociologist and specialist in professional ethics who is also credentialed in instructional technology. We are investigating ways to help earnest but otherwise technically-focused engineers to become more comfortable and capable of accomplishing this lesson.

\section{Step 2: Gain Confidence}

For Keller [21] gaining confidence is facilitated by guiding students through one or more opportunities to apply new knowledge along with closely coupled feedback and coaching. Some of this is accomplished for students actively participating in the step 1 activity above. Engaging everyone at some level through an assignment allows students to dig more deeply into their projects and the five ethical frameworks in a way that links the necessary elements of their engineering projects with the equally necessary components of ethics. This is assigned for presentation to the class two weeks from the classroom session as described above.

Prior to independent analysis of their projects, students are guided through an application of an online tool provided by Markkula [20] to demonstrate a way to imbricate the use of ethical frameworks in a way that reinforces networks between them, and exposes ethical weak points and dilemmas, and showing where they may — intentionally or unintentionally — "game" the process. This demonstrates that an applied ethics approach is a systematic analytic process and not — as one student suggested "loosey-goosey feel-good b $\mathrm{t}^{\prime \prime}$.

Requiring students to present their analysis to their peers in class and receive coaching and feedback right then and there allows the instructors to help students build confidence in their new knowledge and skills at assembling stable ethical scaffolds, and to steer their projects accordingly. From their analysis and in-class feedback, students finalize their ethical assessment and how it has affected their projects in their final project report to the faculty member(s) teaching the course and their clients.

Students are also required to encapsulate their ethical analysis and describe how it affected their projects into an end-of-semester "Senior Design Showcase" poster presentation. Both the in-class presentation and end-of-semester poster are graded assignments. 


\section{Assessing Outcomes}

Several methods were used to assess student learning outcomes following from the instruction and activities. First, an in-class anonymous survey was designed and issued in order to assess general acceptance and perceived relevance, confidence, and satisfaction of their learning. ${ }^{10}$ Second, feedback was solicited from clients of the teams in these projects. Third, a clipboard "checkoff" assessment was accomplished during a college-wide poster presentation of all Senior Design projects. Overall, we find mostly positive evidence about relevance (though see the comments below), with indeterminate confidence but appearance of satisfaction for the prospect of including ethical analyses into their engineering process.

\section{Survey Responses}

It should be unsurprising to learn that responses from the courses $(\mathrm{N}=21$ out of $23, \mathrm{~N}=10$ out of $15)$ to the anonymous survey reflected a wide variation of learned outcomes. The occasional gulf between responses provides substantive opportunity for us to see what influence the process had, and what we have to focus on to improve. Here are a few examples ${ }^{11}$ with our comments following each.

Q: List and describe several ways in which completing the applied ethics tool increased your knowledge and understanding of engineering issues.

PA1: I never understood that there were several aspects of ethics that could be boiled down to 5 different categories. Between utility, social justice, virtue, common good, rights, I couldn't have understood the differences if it weren't for the presentation in class and the application itself.

NA2: The applied ethics tool can be manipulated to spit out whatever number you want it to and has zero correlation to the ethical issues of the projects.

In response to NA2 we have to nod "of course!" The application of a technology inherently depends upon the moral commitment of an individual to be honest. Engineering is affected similarly - one can apply engineering to do harm as well as to do good, but this doesn't make engineering itself either meaningless or bad. From this we learn we have to ensure that we start with ethical imperatives as they are built into the unstated norms of engineering. This could be as simple as a review of the basic canons from the NSPE Code of Ethics, or as detailed as case study analyses of tragic ethical breaches in engineering decision-making, such as those noted at the beginning of this paper.

Q: Did the process of completing your ethical analysis prompt realization of something about your project you had not considered in your engineering analysis?

\footnotetext{
${ }^{10}$ The fact this is accomplished in a course and is a "case study" allowed us to receive approval from the university IRB without review.

${ }^{11}$ Our nominal codes for open-ended student responses that follow are "PA" for "positive answer" and "NA" for negative answer.
} 
$\mathrm{Y}: 48 \%$

$\mathrm{N}: 52 \%$

This is remarkable — an unfamiliar analytic tool with unfamiliar concepts results in identification of design factors that were not previously identified by senior level undergraduate engineering students! This suggests that we could help students consider many more relevant factors if we do this all the time.

Q: Which of the ethical frameworks, or set of frameworks, prompted you to realize something about your stakeholders' concerns that you had not considered before the assignment?

$19 \%$ Utility

$25 \%$ Rights

$25 \%$ Virtue

19\% Common Good

$50 \%$ Fairness / Justice

As shown in the response rates, students sometimes picked multiple frameworks. From these responses, we see the "Fairness / Justice" framework provided students with the most opportunity to identify and consider things they had not previously thought to be relevant to them as designers of engineered products. We are not surprised by this because conventional normative-orientations to engineering ethics tend to focus primarily on utility/utilitarianism empirically measurable benefits associated with the efficiency, economy, or material benefit of engineered products - and thus marginalize or even dismiss factors such as the degree to which engineered products treat all stakeholders with relative fairness or justice (the latter being an indicator of how well some thing or some action fulfills legally or socioculturally expected/required benefits or opportunities to stakeholders).

We were surprised to see that $25 \%$ of respondents considered that handling of ethics (of any type) is associated with virtuous conduct on the part of engineers! While $25 \%$ is not a large proportion, identifying that ethics in engineering practice is itself a thing that makes one's engineering "virtuous" is a positive discovery. In this response we identify that there is an added opportunity for us to promote ethics in engineering as something which in and of itself makes one a better and a more valued engineer. We note this is actually also something also identified in the "Fundamental Canons" section of the NSPE Code of Ethics [7], thus something that we should be emphasizing in our curriculum anyway.

Responses to the following question are surprisingly varied. 
Q: Based on your experience with applied ethics in this module of [Senior Design], how could increased knowledge and skill in engineering ethics issues make you a better engineer?

PA1: It allows for a broader and simultaneously more descriptive analysis on the needs, specifications, and overall requirements of the system. It allows the designer to understand the design's effects on the world around it and who all is affected, both positively and negatively. I find this section to be extremely helpful, as it allows us engineers to understand the situation from a completely different perspective, giving us an opportunity to amend any previously misrepresented errors or ideas.

PA2: Ethics is involved in all forms of engineering. Knowing more about ethics will allow me to think of how my decisions will impact more than just myself and my client

PA3: Going through these ethics assignments and presentations, we had to consider things about our project that we never even considered before. Considering ethics as an engineer helps you consider everyone involved and makes you a better engineer creating a better project.

PA4: It gave us more to think about - but as someone who has limited experience with applied ethics it was hard to really think about the broader impacts of our project.

PA5: considering every possibility will make me a better engineer. I know ethics are important but it is impossible to please everybody. there is always going to be something unethical in someones [sic] perspective but minimizing that is the key.

PA6: You, as an engineer, can modify or redesign your project to be more ethical.

NA1: Knowing the ethical impacts of our project only matters if we care. Unless we are working on very specific projects I would be willing to bet that the ethics of a project will not be considered. It will just be a matter of can it be done. So if we want to skip around with daisies and rainbows then this unit was a great use of our time. I already get berated by my mother-in-law, I don't need to be paying for some random dude to be a no man. Stop trying to make up for where parents dropped the ball.

NA2: The three weeks we spent on this module was overwhelmingly a waste of time. I do not believe I will use any of the tools or material learned in this module as an engineer. Major ethics issues involved in designing do need to be looked at but are mostly common sense. [...]

These responses run a wide range! — PA1 makes the very apt identification that ethics produces a primarily descriptive analysis which could/should influence the design specifications and requirements. This observation leads us to consider that these lessons and activities should be placed much earlier in the semester, before substantive technical work has begun. This individual 
also notes that the ethics analysis leads to a "completely different perspective" than afforded by a more technical engineering process. Similar concepts are identified by both PA2 and PA3. PA4 tells us that more experience with the concepts and process, and application of the results, is necessary. This suggests that — in addition to inserting ethics modules in courses throughout the entire degree plan - that there could be multiple ethics checkpoints through the semester. PA5 approaches ethics from the well-developed rationality of an engineer! There are always tradeoffs to be considered and with the instruction and practice provided, this student indicates that it is possible to "engineer" a maximization of ethics while actively minimizing harms (this is something we would hope for!) Similarly, PA6 concludes that one can actually use an ethical critique of the project to help make decisions that affect the technical and ethical qualities of engineering!

These positive responses are heartening. We see individuals actively fitting new and (probably still very) unfamiliar content into their developing engineering practice. Incorporating tools to improve ethical outcomes into the design process is exactly what we are aiming to facilitate!

Both NA1 and NA2 seem to be telling us that ethics is someone else's issue and not something the engineer has to worry about. We know from the NSPE Code of Ethics [7] and the substantive work done in engineering ethics that this is not the case, but the bigger issue for us in our efforts is that our instruction and activities have not successfully made the case to all students that engineers have an effect on the world and have to be wary of these effects. ${ }^{12} \mathrm{We}$ are addressing this issue with the development of self-paced modules that follow a programmed instruction model which provides both contextual information and instruction with customized feedback, and guided practice in making generalized decisions that apply to individualized cases (for example, see [24]). These modules will be available online so they may be assigned in a "blended" style classroom that reserves classroom time for crucial interaction between faculty and students. The blended classroom method has shown to be effective in this context for this purpose [25].

\section{Feedback from Project Clients}

While project clients did not normally provide feedback related to the ethics content students built into their project reports, on some occasions, they did so. When they do this feedback includes information about the benefits of students' accounting for ethical issues in their work.

For example, one team's project was completed for a client in a government agency. The client remarked that — in addition to expected technical accomplishments - the Senior Design students had identified and addressed a problem he had long considered an ethical issue. Laboratory personnel at that agency were previously required to "babysit" the equipment during

\footnotetext{
${ }^{12}$ Virtually everyone with whom we have shared these and other negative comments tell us that we should not expect to convince everyone. We have begun to think of our purpose as somehow analogous to the concept of "herd immunity" - if enough of our students walk away with greater attention to the topic, the perception that it is relevant for them as engineers, and confidence and satisfaction in their use of tools to apply ethical analysis, then perhaps we can hope that the whole population of engineers is oriented enough to ethics that we have benefit overall.
} 
experiments and in so doing waste taxpayer dollars when they could be doing other work appropriately matched to their knowledge and skills.

In this case, based on the students" application of "full stack ethics" their project was expanded to include creation of (otherwise very simple) equipment that could automate some of what engineering personnel previously had to do by hand, and allow remote monitoring of other functions. The client's feedback to the team noted how their ethical analysis had successfully identified a point in the process that required highly skilled engineering personnel to monitor a mundane process in a secure area of the facility rather than focus their attention on tasks that required their technical expertise. The student team had classified this use of engineers' time as wasteful from the standpoint of "utility" and their design of simple equipment to permit non-technical staff to monitor the process from a remote location was in the service of improving the "utility" of the human-technology system in the facility. The student team also noted that this attention to improving efficiency and utility was also reflective of what they called "engineering virtue" - in this case saving money and time by allowing non-technical personnel to perform work they were previously unable to do.

Together these innovations provided the client (and taxpayers) with increased efficiency and appropriate attention to workers' skills and knowledge. The fact that these were added to the project only after the ethical analysis of the work and what could be accomplished during the semester shows how ethics and engineering come together even in very basic situations.

Upon seeing this feedback from the client, the course instructor — an individual with many years of professional experience in his engineering specialty - reported that he was both pleasantly surprised that the ethical analysis had produced improved value for the customer, but also a bit embarrassed that he had not identified the same thing when he was advising the team. This highlights how even highly experienced engineering professionals can gain insight through the application of even basic ethical analysis of a project.

We can also consider that the College of Engineering and other students are clients of the students' work insofar as they see the work displayed in the annual "Senior Project Showcase" of students' work. Additionally, the disciplinary departments in which these students are studying are also clients of the students' work, because projects become products that are included in materials used to support ABET accreditation reviews. More detail on these is provided below.

\section{Senior Project Showcase}

As mentioned above, all students are expected to present their Senior Design project in the form of a poster, in a college-wide "Senior Project Showcase." The MBE department performs a "clipboard assessment" of student posters during this showcase. The clipboard assessment addresses criteria both part of the official curriculum of the course, and items that must be documented for subsequent ABET re-accreditation efforts. Assessment of ethics involves a "check off" from the person performing the assessment so it is only a nominal indication that there was something related to an ethical analysis on the poster. All projects being presented at the showcase received a positive checkoff in this assessment. 
Subsequent to the showcase, non-systematic conversations with project teams in the moments before their class started allowed us to identify that it was not an uncommon occurrence for viewers at poster stations remarked about the ethical analysis reported on a poster. In one case, a viewer who is a representative of a cognate discipline spent what was reported to be "tens of minutes" asking students about the ethics of placing a solid compost processing facility close to a waterway commonly used for personal recreation (the project had to do with mechanical processing of the material). The team described how they highlighted the economic value of consolidating the processing of organic material in one location and the common good produced by the ability to then offer processed material for safe compost. They also showed the visitor how they had accounted for collection of runoff and below ground effluent so it never reached the waterway. The team leader proudly told the class how they were able to convince the visitor that they were engineers who "took care of the public" and not just "hired guns" for a client. Others in the class verbally appreciated their story and remarked how this underscored the virtue of accounting for ethics in engineering practice. This sort of case example is something we can use in future classes to underscore how ethics is embedded into engineering in a way that the technical parts well, and uses the technical parts to ensure that all stakeholders in a project are considered and protected.

\section{Looking Ahead}

The above shows mixed success for this approach to introducing and practicing an applied orientation to ethics for undergraduate students in Senior Design courses across two different engineering disciplines. Where we can be critical of our accomplishments, we still have feedback that points to particular areas for improvement. With both we can begin to plan for expanding and embedding this approach (a) across more engineering disciplines, and (b) into other courses in disciplinary engineering curricula.

The first author has already begun to introduce the same strategies as described above in vertically-integrated courses in a non-disciplinary-specific "Engineering Plus" degree in Boise State University [26](see also http://coen.boisestate.edu/eplus/). This program merges students from first through fourth year into a series of design-focused, project-based courses (what is called the "design spine" of the curriculum). By introducing ethics into this course, students at each level of their undergraduate studies are engaged in instruction and project activities that blend ethics into engineering design in a spiral-type curriculum that has already shown promise in engineering education [27].

Students in Engineering Plus who received the first delivery of this instruction and application of "Full Stack Ethics" demonstrated nuanced understanding of the tension between utilitarian and justice ethics. One team of students working on a project to create a tool to aid a physically disabled highschool student, presented a utilitarian calculation which prioritized the Aristotellian perspective on justice that we should "treat equals equally and unequals unequally" [28] — a position that upends a more common ableist orientation that one should aim only for maximizing benefits for the many at the expense of the few. 
Similarly, an Engineering Plus student in this class noted on the anonymous course feedback form that while he had taken an ethics course in the Philosophy department, he was puzzled by their non-systematic advice on how to weigh and value different normative frameworks. This student noted how the systematic approach presented in class provided something that he saw was much more consistent with the design-focused engineering process he was learning in the class and from his other engineering instructors. The goal of making professional ethics continuous with other essential engineering processes thus appears to have been successfully met. These identified successes in the design spine of the undergraduate Engineering Plus curriculum provides a warrant to continue to include this content there, and to provide students with multiple opportunities to apply "Full Stack Ethics" over their undergraduate experience. These provide us with optimism to consider that starting ethics instruction earlier in their undergraduate experience, and spiraling it through the curriculum could be a major positive influence and response to even the critical (perhaps cynical) comments noted earlier.

There is no similar "design spine" in the curricula for other engineering majors at Boise State University. However, every other engineering major at Boise State University has a Senior Design course and these are logical next-sites for the lessons and activities described here. Some of these courses are distributed in a two-semester sequence, which allows more opportunity for instruction, practice, and feedback, and perhaps even multiple iterations. In at least one engineering department, the Senior Design course is offered only as a one-semester experience and dovetailing ethics content into this course will be more of a challenge. This warrants a decision to refine the curricula in courses where it is already included and in other Senior Design experiences that spread across two semesters, so that we can identify the most influential content and activities before attempting to incorporate it into the more compressed course. Ongoing developments in that process will be continually reported.

Incorporating elements of professional ethics across courses throughout the entire curriculum will invariably be more challenging, both from the standpoint of identifying how to embed applied ethics content with course-specific technical and other considerations, and from the standpoint of more administrative matters that both innovate and maintain required elements. We start with the idea that this will benefit from the standpoint of the spiral-curriculum [27], where entry-level content and practice is introduced early, and successively more complex content and ethical issues are introduced in successively more advanced courses. As above, our ongoing developments will be reported as possible.

\section{References}

[1] C. Fleddermann, Engineering Ethics, 4th Edition. London: Pearson, 2011.

[2] C. Harris, M. Pritchard, M. Rabins, R. James, and E. Englehardt, Engineering Ethics: Concepts and Cases, Fifth. Boston, MA: Wadsworth, Cengage Learning, 2014.

[3] M. Minch and C. Weigel, Living Ethics: An Introduction, Second. Boston, MA: Wadsworth, Cengage Learning, 2012.

[4] S. Starrett, A. Lara, and C. Bertha, Engineering Ethics: Real World Case Studies. Reston, VA: American Society of Civil Engineers Press, 2017.

[5] M. Winston and R. Edelbach, Society, Ethics, and Technology, Fourth. Boston, MA: 
Wadsworth, Cengage Learning, 2012.

[6] E. Nordenhaug and J. Simmons, "The Outsourcing of Ethical Thinking," J. Hum. Values, vol. 24, no. 2, pp. 138-149, 2018, doi: DOI:10.1177/0971685818765284.

[7] NSPE, "NSPE Code of Ethics for Engineers." National Society for Professional Engineers, Jul-2019.

[8] S. Vallor, Technology and the Virtues: A Philosophical Guide to a Future Worth Wanting. Cambridge: Oxford University Press, 2016.

[9] M. Ghorbani, A. Maciejewski, T. Siller, E. Chong, P. Omur-Ozbek, and R. Atadero, "Incorporating Ethics Education into an Electrical and Computer Engineering Undergraduate Program," in ASEE Annual Conference, Salt Lake City, UT, 2018.

[10] M. Bazerman and A. Tenbrunsel, Blind Spots: Why we fail to do what's right and what to do about it. Princeton, NJ: Princeton University Press, 2012.

[11] M. Fretwell, E. Abbott, D. Winiecki, and N. Salzman, "Influencing Inclusion, Diversity, and Social Justice in Undergraduate Computer Science: Knowledge, Hegemonic Power, Performance, and Uncertainty of the Status of Membership Status," presented at the American Sociological Association (ASA), New York, 2019.

[12] M. Fretwell, E. Abbott, D. Winiecki, and N. Salzman, "Influencing Inclusion, Diversity, and Social Justice in Undergraduate Computer Science: Knowledge, Hegemonic Power, Performance, and Uncertainty of the Status of Membership Status," Forthcoming.

[13] E. Abbott, M. Fretwell, R. Hinrichs, N. Salzman, and D. Winiecki, "Peer Networks Built Around Common Experiences Stabilize Other Things Too: The Durability of Hegemonic Bias in Undergraduate Computer Science Education," Sociol. Perspect., Submitted for review.

[14] D. Winiecki and N. Salzman, "Analyzing and Working-Out Ways of Addressing Problems of Social-Justice in an Engineering or Computer-Science Context. Presented at the . Arlington, VA.," presented at the 2019 NSF REDCON (Revolutionizing Engineering \& Computer Science Department CONference), Arlington, VA, 04-Nov-2019.

[15] D. Winiecki and N. Salzman, "Teaching Professional Morality \& Ethics to Undergraduate Computer Science Students through Cognitive Apprenticeships \& Case Studies: Experiences in CS-HU 130 'Foundational Values'.," Comput. Sci. Eng., Submitted for review.

[16] D. Winiecki et al., "Revolutionizing the Culture of Computer Science Education and Beyond," in RESPECT 2018 Proceedings, Baltimore, MD, 2018.

[17] D. Winiecki, N. Salzman, T. Andersen, A. Jain, D. Zhu, and C. Siebert, "Incorporating Focused Professional Skills, and Inclusion, Diversity \& Social Justice into the Computer Science Curriculum," in REDCON 2018, Arlington, VA, 2018.

[18] E. Bell and H. Willmott, "Ethics, politics and embodied imagination in crafting scientific knowledge," Hum. Relat., vol. OnlineFirst, 2019, doi: https://doi.org/10.1177/0018726719876687.

[19] C. Whitbeck, "Teaching ethics to scientists and engineers: Moral agents and moral problems," Sci. Eng. Ethics, vol. 1, no. 3, pp. 299-308, 1995, doi: https://doi.org/10.1007/BF02628805.

[20] Markkula Center for Applied Ethics, "A Framework for Ethical Decision Making," 01-Aug-2015. [Online]. Available: https://www.scu.edu/ethics/ethics-resources/ethical-decision-making/a-framework-for-ethic 
al-decision-making/. [Accessed: 01-Jan-2017].

[21] J. Keller, Motivational Design for Learning and Performance: The ARCS Model Approach. New York: Springer, 2010.

[22] A. Cohen and C. Wellman, Eds., Contemporary Debates in Applied Ethics. London: Blackwell, 2005.

[23] Markkula Center for Applied Ethics, "Making an Ethical Decision: A practical tool for thinking through tough choices," Making an Ethical Decision, n.d. [Online]. Available: https://www.scu.edu/ethics-app/. [Accessed: 01-Dec-2015].

[24] C. A. Chung and M. Alfred, "Design, Development, and Evaluation of an Interactive Simulator for Engineering Ethics Education (SEEE)," Sci. Eng. Ethics, vol. 15, no. 2, pp. 189-199, Jun. 2009, doi: 10.1007/s11948-008-9109-y.

[25] G. Pfeifer and K. Billiar, "Teaching Ethics in the Context of Engineering Courses: A Blended Approach of Theory and Practice," in 124th ASEE Annual Conference and Exposition, Columbus, $\mathrm{OH}, 2017$.

[26] V. Stieha, N. Salzman, and A. Moll, "Voices of Our Students: Using Evidence-Based Methods to Inform a Multidisciplinary Engineering Program Design," in 2019 ASEE Annual Conference \& Exposition, Tampa, FL, 2019, pp. 26138-1-26138-17.

[27] D. DiBiasio, W. M. Clark, A. G. Dixon, L. Comparini, and K. O'Connor, "Evaluation of a spiral curriculum for engineering," in FIE'99 Frontiers in Education. 29th Annual Frontiers in Education Conference. Designing the Future of Science and Engineering Education. Conference Proceedings (IEEE Cat. No.99CH37011, 1999, vol. 2, pp. 12D1/15-12D1/18 vol.2, doi: 10.1109/FIE.1999.841657.

[28] Markkula Center for Applied Ethics, "Justice and Fairness," 2018. [Online]. Available: https://www.scu.edu/ethics/ethics-resources/ethical-decision-making/justice-and-fairness/. [Accessed: 22-Jan-2020]. 